\title{
Initial Findings of Breast Cancer Risk Factors from a Survey Conducted at Pauls Stradins Clinical University Hospital
}

\author{
Agnese Dzervite*, Maruta Pranka*, Tana Lace**, Ritma Rungule***, Janis Gardovskis*,**, Edvins Miklasevics*,** \\ * Riga Stradins University Oncology Institute, Latvia \\ ** Pauls Stradins Clinical University Hospital, Latvia \\ *** Riga Stradins University Department of Sociology and Psychology, Latvia
}

\begin{abstract}
Summary
Introduction. Several risk factors for breast cancer have been documented based on epidemiological studies conducted over the last several decades - familial history of breast cancer, particular gene mutations, early menarche, late menopause, late age at first childbirth, use of oral contraceptives and hormone replacement therapy, absence of breastfeeding, alcohol use, smoking, obesity and physical inactivity
\end{abstract}

Aim of the study. Register data on breast cancer risk factors among the Latvian population and analyze it in relation to age of diagnosis.

Materials and methods. This paper presents quantitative survey data collected from April 2010 to June 2011 at the Pauls Stradins Clinical University hospital from 150 patients undergoing breast cancer treatment.

Results. A small correlation could be seen between age and patient menarche $(0.1541 ; p=0.0749)$, as well as menopause onset (0.1286; $p<0.0001)$. Hormonal replacement did not show any correlation with age, yet hormonal contraceptives had a moderate correlation with a statistical significance $(-0.4988 ; p=0.0001)$. Lifestyle risk factors had higher correlations with age of diagnosis than reproductive factors. A moderate correlation could be seen for age and smoking $(-0.37289 ; p<0.0001)$. A similar moderate correlation existed for age and use of alcohol $(-0.31095 ; p=0.0012)$. Our survey found that no significant correlation exists between age of diagnosis and number of pregnancies, number of births and number of abortions. We found no significant correlation between age and length of breast feeding.

Conclusions. From current available data gathered in our study it can be concluded that for the Latvian population breast cancer risk is more associated with lifestyle factors than reproductive.

Key words: breast cancer; risk reproductive factors; lifestyle factors.

\section{INTRODUCTION}

Breast cancer is the most common form of cancer in women worldwide (16). Several risk factors for breast cancer have been documented based on epidemiological studies conducted over the last several decades. While it is difficult to identify a specific risk factor contributing to the development of breast cancer in a single patient, quantitative studies have identified the most likely factors to increase risk of developing breast cancer during lifetime to be familial history of breast cancer, particular gene mutations (BRCA1, BRCA2 and TP53), early menarche, late menopause, late age at first childbirth, use of oral contraceptives and hormone replacement therapy, absence of breastfeeding, alcohol use, smoking, obesity and physical inactivity $(5,6,2,7)$. Besides genetic, reproductive and lifestyle factors, breast cancer risk varies greatly based on ethnic background and geographic locations, even within Europe it has been noted that highest rates of breast cancer are in the West and nearly twice lower in the East (5). Research analyzing differences in breast cancer incidence between developed and developing countries has shown the significance of diet, later childbirth, lower and shorter breastfeeding (11).
Very little research is available on the epidemiology of breast cancer risk factors in Latvia (6) with most research being done in the field of surgery and biomedicine. A potential source of information is the national register on patients with specific diseases where breast cancer data includes a notation of the patient having been linked to the following risk factors - family history of cancer, abortions, smoking and use of alcohol - but this data is limited for a multifaceted epidemiological analysis of breast cancer risk.

\section{AIM OF THE STUDY}

Register data on breast cancer risk factors among the Latvian population and analyze it in relation to age of diagnosis.

\section{METHODS}

This paper is based on a survey of breast cancer patients conducted from April 2010 until June 2011, during this time 150 surveys were collected.

The quantitative interviewer administered survey of breast cancer patients was conducted at the Pauls Stradins Clinical University Hospital, where all patients after a mastectomy surgical operation were approached, 
informed about the study and asked to participate the day after surgical treatment. The 10 page questionnaire was constructed to include crucial information on patient demographics, reproductive health, life-styles, experience with and information on medical check-ups, as well as quality of life.

Descriptive statistical data in this paper are presented as means, frequencies, proportions and percent of included patients. Reported confidence intervals were calculated at a 95\% confidence level. Statistical significance was calculated using the Whitney Mann U test.

This study was approved by the Ethical Committee of Riga Stradins University and all patients involved signed informed consent forms.

\section{RESULTS}

The national cancer register in the year 2010 recorded 1057 breast cancer patients (13) and at Pauls Stradins Clinical University hospital in 2010 a total of 195 breast operations were performed. During the period between April 2010 and June 2011 a total of 150 patients were interviewed, one was male and the rest female.

The average age of patients was 62 (95\% CI: 49-75) and ranged from 28 to 86 years. Approximately half of the patients were the age of 65 and older (48\%, CI: 40-56). Nearly half of patients (48\%, CI: 40-56) were married or living with a partner, $32 \%$ (CI: 24.5-39.5) were widowed, $13.3 \%$ (CI: 5.8-20.8) divorced and $6.7 \%$ (CI: 2.7-10.7) single. Majority of patients (47.3\%, CI: 39.355.3 ) had a general secondary or vocational secondary education, more than one third (34.7\%, CI: 27.1-42.3) had a university degree, while 18\% (CI: 11.9-24.1) had primary and lower education, yet among patients older than 65 this was characteristic of 33\% (CI: 25.5-40.5). Nearly half of patients $(47 \%$, CI: $39-55)$ were retired and living from state pensions, while 34\% (CI: 26.441.6) were working, 5\% (CI: 1.5-8.5) were housewives, $8 \%$ (CI: 3.7-12.3) were permanently disabled and only 4\% (CI: 0.9-7.1) were unemployed.

\section{Reproductive factors}

As part of our questionnaire we gathered information on several reproductive factors: use of hormonal contraceptives and hormone replacement therapy; number of pregnancies, births and children; length of breastfeeding per child; age for start and end of menstruation; and number of spontaneous and induced abortions.

For most women menstruation ends around the age of 50, with the average age in the developed countries being 51.4 years (4), but distinct geographic and ethnic differences have been recorded around the world, for instance menopause comes slightly earlier in Southern Europe compared with Northern Europe (10). Our research found that the average age of menarche for patients was 14 (SD: \pm 2 ), with only $11 \%$ (95\% CI: 6-17) of women having their menstruation start at the age of 12 or less. The average age of menopause was 50 (SD: \pm $5)$, with only $15 \%$ (CI: $8-21$ ) of women having their menopause at 55 or later (see Table 1).
Regarding use of hormonal medication we found that $21 \%$ (CI: 14-28) of patients had used hormonal contraceptives during their lifetime and 15\% used hormonal replacement therapy. The average age of patients that had used hormonal contraceptives was 49 (SD: \pm 10 ) and for those that did not -65 (SD: \pm 12 ) (see Table 1).

Average number of pregnancies was 3.34 (SD: \pm 2.14 ) with majority of patients having during their lifetime 1-5 pregnancies (77\%, CI: 70-84). The average number of births was 1.72 (SD: \pm 0.96 ) with only $3 \%$ (CI: $3-6$ ) having more than 3 births in their lifetime. In accordance there was an average of 1.65 (SD: \pm 1.73 ) abortions to a patient, with an average 1.40 (SD: \pm 1.58 ) induced and only 0.25 (SD: \pm 0.58 ) spontaneous abortions (see Table 1). Of all the abortions, $85 \%$ (CI: 82-89) were induced and 15\% (CI: 11-19) were spontaneous.

Among the surveyed patients the average length of breast feeding during lifetime was 11 months (SD: \pm 9 ), with $62 \%$ (CI: 54-70) having breastfed only up to 12 months and 38\% (CI: 30-46) longer (see Table 1).

Table 1. Reproductive risk factors

Confi- Ave. St. dence Int. Age Dev.

\begin{tabular}{|ll|l|ll|l|l|}
\hline $\begin{array}{l}\text { Hormonal } \\
\text { contracetives }\end{array}$ & Yes & $21 \%$ & $14 \%$ & $28 \%$ & 49 & 10 \\
\cline { 2 - 7 } & No & $79 \%$ & $72 \%$ & $86 \%$ & 65 & 12 \\
\hline
\end{tabular}

\begin{tabular}{|ll|r|rr|r|c|}
\hline $\begin{array}{l}\text { Hormonal } \\
\text { replacement } \\
\text { therapy }\end{array}$ & Yes & $15 \%$ & $9 \%$ & $21 \%$ & 60 & 10 \\
\cline { 2 - 6 } & No & $85 \%$ & $79 \%$ & $91 \%$ & 62 & 14 \\
\hline
\end{tabular}

\begin{tabular}{|c|c|c|c|c|c|}
\hline \multirow[t]{10}{*}{ Pregnancies } & 0 & $8 \%$ & $4 \% \quad 12 \%$ & 63 & 15 \\
\hline & 1 & $11 \%$ & $6 \% \quad 16 \%$ & 59 & 16 \\
\hline & 2 & $20 \%$ & $14 \% 26 \%$ & 60 & 14 \\
\hline & 3 & $19 \%$ & $12 \% \quad 25 \%$ & 63 & 13 \\
\hline & 4 & $15 \%$ & $10 \% \quad 21 \%$ & 62 & 13 \\
\hline & 5 & $11 \%$ & $6 \% \quad 16 \%$ & 61 & 13 \\
\hline & 6 & $8 \%$ & $4 \% \quad 12 \%$ & 61 & 12 \\
\hline & 7 & $6 \%$ & $2 \% \quad 10 \%$ & 67 & 11 \\
\hline & 9 & $1 \%$ & $-1 \% \quad 3 \%$ & 69 & 6 \\
\hline & 12 & $1 \%$ & $-1 \% \quad 2 \%$ & 61 & - \\
\hline
\end{tabular}

\begin{tabular}{|l|r|r|rr|c|c|}
\hline Births & 0 & $9 \%$ & $5 \%$ & $14 \%$ & 60 & 17 \\
\hline 1 & $31 \%$ & $24 \%$ & $39 \%$ & 64 & 12 \\
\hline 2 & $41 \%$ & $33 \%$ & $49 \%$ & 60 & 13 \\
\hline 3 & $15 \%$ & $9 \%$ & $20 \%$ & 65 & 14 \\
\hline 4 & $3 \%$ & $0 \%$ & $5 \%$ & 53 & 8 \\
\hline 5 & $1 \%$ & $-1 \%$ & $2 \%$ & 77 & 0 \\
\hline
\end{tabular}




\begin{tabular}{|c|c|c|c|c|c|}
\hline \multirow[t]{5}{*}{ Breast feeding } & $0 \mathrm{~m}$ & $13 \%$ & $8 \% \quad 19 \%$ & 60 & 16 \\
\hline & $1-6 m$ & $25 \%$ & $18 \% \quad 32 \%$ & 62 & 14 \\
\hline & $\begin{array}{l}6- \\
12 \mathrm{~m}\end{array}$ & $23 \%$ & $17 \% \quad 30 \%$ & 60 & 12 \\
\hline & $\begin{array}{l}12- \\
24 \mathrm{~m}\end{array}$ & $25 \%$ & $18 \% \quad 32 \%$ & 65 & 13 \\
\hline & $\geq 24 \mathrm{~m}$ & $13 \%$ & $7 \% \quad 18 \%$ & 61 & 13 \\
\hline \multirow[t]{2}{*}{ Menarche } & $\leq 12$ & $11 \%$ & $6 \% \quad 17 \%$ & 57 & 13 \\
\hline & $>12$ & $89 \%$ & $83 \% \quad 94 \%$ & 62 & 13 \\
\hline \multirow[t]{2}{*}{ Menopause } & $<55$ & $85 \%$ & $79 \% \quad 92 \%$ & 62 & 13 \\
\hline & $\geq 55$ & $15 \%$ & $8 \% \quad 21 \%$ & 55 & 11 \\
\hline
\end{tabular}

\begin{tabular}{|c|r|r|rr|c|c|}
\hline Abortions & 0 & $33 \%$ & $26 \%$ & $41 \%$ & 60 & 14 \\
\cline { 2 - 6 } & \begin{tabular}{|l}
1 \\
2
\end{tabular} & $19 \%$ & $12 \%$ & $25 \%$ & 63 & 15 \\
\hline 3 & $13 \%$ & $8 \%$ & $19 \%$ & 62 & 12 \\
\hline 4 & $4 \%$ & $1 \%$ & $7 \%$ & 60 & 10 \\
\hline 5 & $4 \%$ & $1 \%$ & $7 \%$ & 66 & 14 \\
\hline 6 & $2 \%$ & $-0 \%$ & $4 \%$ & 65 & 5 \\
\hline 7 & $1 \%$ & $-1 \%$ & $2 \%$ & 73 & - \\
\hline 10 & $1 \%$ & $-1 \%$ & $2 \%$ & 61 & - \\
\hline
\end{tabular}

Table 2. Correlation between age and reproductive risk factors

\begin{tabular}{|lc|c|c|}
\multicolumn{2}{c}{ Correlation } & \multicolumn{2}{c}{$\mathbf{( 1 )}$} \\
\hline $\begin{array}{l}\text { Hormonal } \\
\text { contracetives }\end{array}$ & -0.499 & Yes/No & 0.0001 \\
\hline $\begin{array}{l}\text { Hormonal } \\
\text { replacement } \\
\text { therapy }\end{array}$ & -0.057 & Yes/No & 0.2177 \\
\hline Pregnancies & 0.067 & $<\mathbf{3 / \geq 3}$ & 0.3446 \\
\hline Births & -0.001 & $\mathbf{0 / \geq 1}$ & 0.3372 \\
\hline Breast feeding & 0.036 & $<\mathbf{1 2} / \geq \mathbf{1 2}$ & 0.1075 \\
\hline Abortions & 0.080 & $\mathbf{0} / \geq \mathbf{1}$ & 0.1788 \\
\hline
\end{tabular}

\section{Lifestyle factors}

As part of our survey we included also a variety of question related to lifestyle issues: duration and amount of smoking; pattern of alcohol use; weight and height; frequency of physical activity per week.

Among surveyed patients there were 25\% (95\% CI: 18-32) that had been smokers during their lifetime and 89\% (CI: 84-94) had been alcohol users. Average age of those that had smoked was 53 (SD: \pm 12 ), while for those patients that had never smoked -65 (SD: \pm 13$)$. A distinct difference for age of diagnosis was also among patients that were not using alcohol on average 66 (SD: \pm 13 ) and for those that were using alcohol 60 (SD: \pm 13 ) (see Table 3).
The majority of breast cancer patients were overweight, with only $27 \%$ (CI: 20-34) being in the WHO normal body mass index range (BMI: 18.5-25), 37\% (CI: 3045) were overweight (BMI: 25-30) and 35\% (CI: 27$43)$ were obese (BMI: $\geq 30)$. Average age of patients that were in the normal body mass index range was 58 (SD: \pm 14 ), while for those overweight -63 (SD: \pm 12 ). The average height among patients was $1.63 \mathrm{~m}$ (SD: 0.06) and the average weight was $75.63 \mathrm{~kg}$ (SD: 16.36) (see Table 3).

Among the patients that answered about their weekly physical activities (110 patients), half (50\%, CI: 42-58) had no physical activities or just once a week with an average age of 64 (SD: \pm 13$)$, while the other half had physical activities 2 or more times a week $(50 \%$, CI: 42 58 ) with an average age of 59 (SD: \pm 13 ) (see Table 3).

Table 3. Lifestyle risk factors

\begin{tabular}{|c|c|c|c|c|c|c|}
\hline & & $\%$ & $\begin{array}{r}\text { Confic } \\
\text { In }\end{array}$ & ence & $\begin{array}{l}\text { Ave } \\
\text { Age }\end{array}$ & $\begin{array}{c}\text { St. } \\
\text { Dev. }\end{array}$ \\
\hline Smoking & Yes & $25 \%$ & $18 \%$ & $32 \%$ & 53 & 12 \\
\hline & No & $75 \%$ & $68 \%$ & $82 \%$ & 65 & 13 \\
\hline $\begin{array}{l}\text { Use of } \\
\text { alcohol }\end{array}$ & Yes & $70 \%$ & $63 \%$ & $77 \%$ & 60 & 13 \\
\hline & No & $30 \%$ & $23 \%$ & $37 \%$ & 66 & 13 \\
\hline
\end{tabular}

\begin{tabular}{|c|c|c|c|c|c|c|}
\hline \multirow{5}{*}{$\begin{array}{l}\text { Body Mass } \\
\text { Index }\end{array}$} & Normal & $27 \%$ & $20 \%$ & $34 \%$ & 58 & 14 \\
\hline & Overweight & $37 \%$ & $30 \%$ & $45 \%$ & 64 & 14 \\
\hline & Obese I & $22 \%$ & $15 \%$ & $29 \%$ & 64 & 17 \\
\hline & Obese II & $8 \%$ & $4 \%$ & $12 \%$ & 63 & 7 \\
\hline & Obese III & $5 \%$ & $2 \%$ & $9 \%$ & 59 & 9 \\
\hline
\end{tabular}

\begin{tabular}{|ll|l|ll|l|l|}
\hline $\begin{array}{l}\text { Physical } \\
\text { activity }\end{array}$ & Non & $17 \%$ & $10 \%$ & $24 \%$ & 70 & 12 \\
\cline { 2 - 7 } & Low & $33 \%$ & $24 \%$ & $41 \%$ & 61 & 12 \\
\cline { 2 - 7 } & Moderate & $29 \%$ & $21 \%$ & $38 \%$ & 58 & 14 \\
\cline { 2 - 7 } & High & $21 \%$ & $13 \%$ & $29 \%$ & 59 & 16 \\
\hline
\end{tabular}

Table 4. Correlation between age and lifestyle risk factors

\begin{tabular}{|lc|c|c|}
\multicolumn{3}{c}{ Correlation } & \multicolumn{1}{c|}{$(\mathbf{1})$} \\
\hline Smoking & -0.373 & Never/Had & 0.0001 \\
\hline Use of alcohol & -0.311 & Never/Had & 0.0012 \\
\hline Body Mass Index & 0.192 & $\mathbf{< 2 5 / \geq 2 5}$ & 0.0069 \\
\hline Physical activity & -0.235 & $\begin{array}{c}\leq \text { Low/ } \\
\mathbf{\text { Mod}} .\end{array}$ & 0.1788 \\
\hline
\end{tabular}




\section{DISCUSSION}

A large epidemiological study done by Lacey et al. in 2009 showed that increasing age, nulliparity and use of menopausal hormone therapy were positively associated with breast cancer. Yet later age at menarche or menopause were less strongly associated with breast cancer than was expected. There were weak positive associations between severe obesity (8). A study done based on data from the Latvian national register on patients with specific diseases found that among breast cancer patients $10.6 \%$ had prior abortions, $3.7 \%$ smoked, $0.6 \%$ used alcohol (7). Our survey found that no significant correlation exists between age of diagnosis and number of pregnancies, number of births and number of abortions (see Table 2). In 2010 the total national birthrate was 34.4 per 1000 women aged 14-59. The national fertility rate was 1.18, while for breast cancer patients the average number of children was higher (1.72). The national abortion rate was 19.3 with a total of 10820 abortions in the year 2010, from all the abortions $68.7 \%$ were induced and $12.1 \%$ were spontaneous (3). It is not possible to compare data on abortions for a single year and breast cancer patient lifetime abortions, but we can see that among the abortions in case of breast cancer patients there is a higher prevalence of induced abortions (85\%). There are similar difficulties in comparing breast cancer patient data on number of births in a lifetime to the national statistics where we can see that on average the proportion of second child births among all births in 2009 was $34.11 \%$ and third child births - $11.31 \%$, while among breast cancer patients $41 \%$ have had two births and 15\% - three births.

An analyses of 47 international studies done by the Collaborative Group on Hormonal Factors in Breast Cancer showed that relative risk of breast cancer is reduced by $4.3 \%$ (95\% CI: 2.9-5.8) for each year that a woman breastfeeds, in addition to a reducing by $7 \%$ (CI: 5-9) for each birth while being consistent for women from developed and developing countries of different ages, ethnic origins and various childbearing patterns. In this particular study the average age at diagnosis was 50 years, observed patients had fewer births than control groups, there was a greater proportion of nulliparous women and parous women who had never breastfed (1). We found no significant correlation between age and length of breast feeding, on average those having fed less than 12 months were diagnosed with breast cancer at the age of $61(S D: \pm 13)$ and those that breastfed longer were an average age of 64 (SD: \pm 13$)$. A weak correlation can be seen between age and patient menarche $(0.1541 ; \mathrm{p}=0.0749)$, as well as menopause onset $(0.1286 ; \mathrm{p}<0.0001)$. Yet while the hormonal replacement did not show any correlation with age at diagnosis, the hormonal contraceptives had correlation of -0.4988 with a statistical significance of $p=0.0001$ (see Table 2). The national data shows that $15.8 \%$ of all women aged 15-49 used hormonal contraceptives during 2009 (12), this proportion is lower than in our surveyed group $(21 \%)$, but the national level only includes current users in a limited age group while we have surveyed lifetime use of hormonal contraceptives. Our survey of Latvian patients shows that lifestyle risk factors had higher correlations with age of diagnosis than reproductive factors. A moderate correlation of -0.37289 can be seen for age and smoking with a $\mathrm{p}<0.0001$ where on average the age of patients that had never smoked was by 12 years greater. The national level of smoking for females in 2009 was $22 \%$ (17), while among breast cancer patients there were only $7 \%$ (CI: 3-11) current smokers, yet 25\% had smoked during their lifetime. A similar moderate correlation was also for age and use of alcohol $(-0.31095 ; \mathrm{p}=0.0012)$, where patients that had never used alcohol in their life were on average diagnosed with cancer at 4 years later. Among breast cancer patients the proportion of lifetime abstainers was $11 \%$ (CI: 6-16), but among the Latvian female population 13.8\% (data from 2003). Difference between national levels of current abstainers was smaller, yet still in total $31.7 \%$ did not use alcohol in the last 12 months while among breast cancer patients $30 \%(15)$.

A weak correlation $(0.19212 ; \mathrm{p}=0.0069)$ was noted for body mass index, with the average age of patients with a normal BMI being by 5 years less than those who were overweight. This can be attributed to the overall large proportion of older women, but considering women aged 45 and younger among the surveyed - 44\% were overweight. Still compared to national BMI rates in 2008, among surveyed breast cancer patients there was a larger proportion of obese women (22\% national; 35\% surveyed) (18). Previous studies have shown that risk of breast cancer was lowest in lean women (BMI <22.8) who exercised at least four hours per week, but these effects were greater for premenopausal women (14). We found that in our survey for physical activity the correlation was small $(-0.2350 ; \mathrm{p}=0.015)$, with patients that had moderate or high physical activity a week being on average 5 years younger (see Table 4 ). This too can be explained with age specific patterns in physical activity, where the large cohort of older patients was also suffering from other health problems that limited their movement. The evaluation of body mass and physical activity should include a more detailed examination with adjustments to age and physical wellbeing, yet the current sample is too small for viable statistical analysis.

\section{CONCLUSIONS}

From current available data gathered in our study it can be concluded that for the Latvian population breast cancer risk is more associated with lifestyle factors than reproductive. The main impact on age of breast cancer diagnosis was seen from use of hormonal medication, alcohol and smoking. Some impact was also found for early menarche, late menopause, body mass and physical activity, but this data should be adjusted for age, other reproductive and lifestyle factors. To better evaluate several risk factor correlations a greater sample of data on breast cancer patients bust be gathered for further research. 


\section{ACKNOWLEDGMENTS}

This paper is part of the on-going Riga Stradins University Oncology institute research project "a new multidisciplinary research group formation for the study of breast cancer, therapy effectiveness and patient quality of life improvement" and is financially supported by the European Social Fund (2009/0230/1DP/1.1.1.2.0/09/ APIA/VIAA/070).

\section{Conflict of interest: None}

\section{REFERENCES}

1. Collaborative Group on Hormonal Factors in Breast Cancer. Breast cancer and breastfeeding: collaborative reanalysis of individual data from 47 epidemiological studies in 30 countries, including 50302 women with breast cancer and 96973 women without the disease // The Lancet, 2002; 360:187-195

2. Danaei $G$ et al. Causes of cancer in the world: comparative risk assessment of nine behavioural and environmental risk factors // Lancet, 2005; 366: 1784-93.

3. Health in the Baltic Countries 2010. 19th edition // The National Health Service of Latvia [Online] Available at: http://vec.gov.lv/uploads/ files/4f546ace90211.pdf (Accessed: 28.05.2012.)

4. Henderson KD. et al. Predictors of Timing of Natural Menopause in the Multiethnic Cohort Study // Am J Epidemiology, 2008; 167:1287-94

5. IARC. Breast Cancer Incidence, Mortality and Prevalence Worldwide in 2008 // [Online] Available at: http://globocan.iarc.fr/factsheet.asp (Accessed: 07.06.12.)

6. Lacey JV et al. Breast cancer epidemiology according to recognized breast cancer risk factors in the Prostate, Lung, Colorectal and Ovarian (PLCO) Cancer Screening Trial Cohort // BMC Cancer, 2009; 9 (84)

7. Kazarjana A, Baltina D, Mackevics V, Zeidlers I. Women with breast cancer in Latvia: analyses of data from specific disease patient register (abstract in Latvian) // In: Riga Stradins University 2011 Scientific conference. Riga, Latvia: 2010 March 1819 , pp 259

8. Key TJ, Verkasalo PK, Baks E. Epidemiology of breast cancer // The Lancet Oncology, 2001; 2:133140
9. Latvian Cabinet of Ministers. State family policy guidelines 2011-2017 (in Latvian) // [Online] Available at: http://polsis.mk.gov.lv/view. do?id=3583 (Accessed: 12.06.2012.)

10. Palacios S., et al. Age of menopause and impact of climacteric symptoms by geographical region // Climacteric, 2010; 13:419-428

11. Peto J. Cancer epidemiology in the last century and the next decade // Nature, 2001; 41 1: 390-395.

12. The Center of Health Economics. Mother and Child Health 2009. $11^{\text {th }}$ edition // Zile I, editor. Riga: 2010 [Online] Available at: http://vec.gov.lv/uploads/ files/4dd379f8d59d7.pdf [Accessed: 05.06.2012.]

13. The Centre of Health Economics. Oncology Statistical data on number of patients distributed by region, cancer location, gender and age groups from 2007 to 2010 (in Latvian) [Online, updated 25.11.2011] // Available at: http://vec. gov.lv/uploads/files/4e0f3fdfedfc8.doc (Accessed: 05.02.2012.)

14. Thune I, Brenn T, Lund E, Gaard L. Physical activity and the risk of breast cancer // The New England Journal of Medicine, 1997; 336(18): 1269-1275

15. World Health Organization. Global Status Report on Alcohol and Health $2011 / /$ [Online] Available at: http://www.who.int/substance_abuse/ publications/global_alcohol_report/msbgsreur.pdf (Accessed: 12.06.2012.)

16) World Health Organization. World Cancer Report 2008 // Boyle P, Levin B, editors. Lyon: WHO Press, 2008

17. World Health Organization. World Health Statistics 2012 // Geneva: WHO Press, 2012 [Online] Available at: http://www.who.int/gho/publications/world_ health_statistics/2012/en/index.html (Accessed: 04.06.2012.)

18. World Health Organization. Overweight/obesity 2008 // [Online database] Available at: http:// gamapserver.who.int/gho/interactive_charts/ ncd/risk_factors/overweight_obesity/atlas.html (Accessed: 04.06.2012.)

\section{Address:}

Agnese Dzērvīte,

E-mail: agnese.dzervite@gmail.com

Maruta Pranka,

E-mail: pranka@latnet.lv

Dzirciema 16, Rìga, LV 1007 